Minist er of Labour, Employment and Welfare, Malta

\title{
Gentlemen :
}

Mr Chairman, Distinguished Guests, Ladies and

It is a pleasure to have the opportunity to speak this afternoon at the closing ceremony of this Seminar opened by my colleague, the Hon. Miss Agatha Barbara, Minister of Education and Culture.

This Seminar is the fourth Commonwealth Youth Seminar. The firstwas held in Nairobi, in 1969, and it was then considered as an experiment. The Malta Seminar, however, can also be considered to be another experiment. In fact, while the main purpose of the other three Seminars was to bring together the ideas and experience of experts in the field of youth development in several member countries of the Commonwealth, the Malta Seminar has been limited to the problems of youth in one particular country, in our case, Malta, thus giving the opportunity to young people themselves to participate and discuss freely their own problems with adults and experts and to put forward their ideas and suggestions for the solution of these problems. This method of approach has in my view its own advantages. Being direct, it is bound to give a more genuine and a clearer picture of the various aspects of the problems of youth with the consequent result of a better evaluation of their importance. In this way those responsible for the guidance and welfare of young persons will be placed in a much better position to provide the right solutions.

I am sure that during the period of the last three days you have discussed several important and interesting questions, all of which revolved round the extremely important theme, namely "Youth. and Development in Malta". In every country, at all times, youths have been connected with problems which in their turn were connected with education, employment, training, plan planning programmes, involvement in national and political issues and last but not least, finance.

1 understand that the subject about prospects of employment in Malta has formed one of the main items of discussion, as was to be expected. In fact, unemployment is one of the major 
problems of youth in developing countries, and I dare say, also in developed countries. Naturally, Malta is not an exception.

In her opening address, my honourable colleague, the Minister of Education and Culture, pointed out some of the measures which the present Government intends to introduce for the solution of unemployment and I understand that other speakers have explained to you some of the facilities which my Ministry provides to help young people in their search for employment. As you well know, Malta is a very small island with a very dense population and consequently the effects of unemployment, even when it is of a small dimension, can be felt very acutely. For this reason, the present Government is well aware of this problem and is determined to tackle it with vigour.

By the end of last year, the working population in Malta stood at 109,000 persons, of which 103,000 were in gainful employment, while 6,000 were registered as unemployed. The gainfully employed persons are made up of 80,250 males and 22,830 females. Private industry alone provides for 75,860 jobs and the Malta Government, including the Malta Land Force, employs 21, 180 persons, while the United Kingdom Defence Departments employ 6,000 persons. Recently there has been a sudden and sharp increase in the number of unemployed persons. The figure last month was in fact 8,000. This sudden increase was not due to any Government policies, but was mainly due to the recent political crisis which has now been happily settled to the greatest benefit of our country. However, it should be noted that the number of unemployed persons has been steadily increasing ever since 1970, mainly as a consequence of the fact that the building boom, which came out of the blue in 1965, has been declining ever since that year.

In this situation of mounting difficulties the present Government took office, and in order to solve the problems of unemployment it intends to adopt certain measures which could be qualified under two categories, namely, the long-term and the short-term ones.

Among the first I would mention: one, the acceleration of industrial development by the completion, at the earliest possible time, of the projects connected with the infrastructure of the local industry; two, the introduction of trade schools; three, the organisation and exten sion of the present indu strial training centres; and four, the intensification of vocational guidance. 
The success of these measures depends largely on planning. Planning, however, is impossible without a firm basis of reliable and up to date statistics which in turn must themselves be planned. Among these, labour statistics figure very prominently, in fact the se are essential for the formation of an employment policy and manpower budgeting. I am afraid that the present system of labour statistics is faulty in many respects and presents serious weaknesses in the collection of reliable information. For this reason legislation has been recently introduced by the present Government in order to reorganise and establish on a firm basis the collection of labour statistics. Important information will henceforth be collected directly from employers in both the public and private sector about their likely future needs for qualified manpower, thus creating a continuous monitoring of trends in the demand for, and the supply of manpower of different kinds, by the liaison between my Ministry and the other Ministries.

In the process of accelerating industrial development, both Trade Schools and Industrial Training Centres will be guided by the principle that the necessary skills should be imparted to young persons in accordance with the trends of the needs of the local labour market. Personally, I attach great importance to vocational guidance, but I am afraid that not enough use is being made of this facility. Vocational guidance should prove of great help to young persons, especially school leavers, who are facing the problem of adjusting themselves into the working population. It very often happens that because of the ignorance of the nature of a particular job and also because of certain unfounded prejudices, a young person chooses the wrong job with the consequent frustration and hardship. At other times a young person may lose the opportunity of obtaining a suitable occupation due to lack of information about its existence. All the se problems and difficulties could be alleviated and very often solved through vocational guidance. I do not wish to give the impression that vocational guidance is able to exert any magical influence on the thinking of young persons, but it can certainly influence them in the right direction. This applies even more forcibly to a small country like Malta where fortunately we have no problems connected with the geography of transport, and it is easier, therefore, to understand the nature and extent of the labour market in order to establish the approximate number of openings in each occupation. I was, therefore, very glad to hear that this subject has aroused special interest among the young participants in this Seminar. It is a good sign and it augurs well for the future, not only because it encourages us to proceed with the 
improvement of our vocational guidance facilities but also because it could strengthen the belief of young persons in the importance and value of the use of this facility.

I said that short-term measures were also being introduced. Among these I feel I should mention the establishment of an Emergency Labour Corps. I am not aware whether this item has formed part of your discussions or not, and therefore, I am not in a position to pass any comments on your reaction to it. However, it is a subject which has aroused controversy both in Parliament and in the local press. In my view, however, the opposition and criticism against this Legislation have been based on a misconception of the true aims and purposes behind it. In fact the aim of the Emergency Labour Corps is to provide work and training to our unemployed persons, the bulk of whom are young persons. It is not intended to solve the unemployment problem, because its role' is to alleviate it. It is not a long-term measure but a short-term one and therefore it cannot be critised as an inadequate means of solving our unemployment problems because it was never intended to be so.

Much criticism has also been levelled at the element of discipline introduced in this Corps; it is, however, a well accepted principle that if efficiency is to be achieved, there must be discipline. Another aspect of this question is the protection of the rights of the members of the Corps as workers and members of trade unions. I must assure you that there will be nothing in the regulations which would deprive the volunteers of any of their basic rights, but the fact must be taken into account that work is only part of the service in this Corps, that is only a few days a week, the rest of the week being devoted to industrial training and military training. Here I must make it clear that there is no idea of building up any military force in the ordinary sense of the word; military training will only consist in foot-drill and physical training. There is no ambition to form a military army to attack any of our neighbours. I am sure that if the critics of this legislation were aware of what was going on in other parts of the Commonwealth, they would not have wasted so much energy in trying to scorn the true objects behind the establishment of this Corps. Substantially, it is similar to National Youth Services set up in other member countries of the Commonwealth. Therefore, I wish to confirm what my colleague, the Hon. Minister of Education and Culture, Miss Agatha Barbara, stated in her opening address, that this Corps is a practical and beneficial step towards the relief of our present unemployment problem. 
Before concluding, I wish to thank the members of the Commonwealth Secretariat who have helped us immensely in guiding this Seminar, by putting at our disposal their vast experience, namely, Dr. James Maraj and Mr. James Eedle. I thank also the two guest speakers, namely His Excellency Josua Rabukawaqa and $\mathrm{Mr}$. Samuel Kihumba, as well as all the local speakers, all of whom have enlightened this Seminar with their expert knowledge.

I thank also all the members of the local Inter-

governmental Committee and all participants, especially the young ones, who I am sure have encouraged the organisers to repeat the experiment of allowing young persons a greater and fuller participation in the discussion of their own problems.

Finally, I hope that the work of this Seminar together with that of the other three Seminars will prove fruitful at the forthcoming Commonwealth Conference of Ministers concerned with youth matters and will help in the formulation of national policies and encourage regional and Commonwealth co-operation. 